\title{
Aspect and Adverbials
}

\author{
Janet Hitzeman
}

University of Rochester

The aim of this article is to introduce a treatment of the prepositions heading temporal adverbials as binary operators which select for certain aspectual properties of their arguments and order these arguments temporally. I extend the Dowty [1986]/Taylor [1977] characterization of the aspectual classes to include certain basic properties of events and argue that a treatment of the selectional properties of temporal adverbials based on such a framework avoids certain incorrect predictions. I motivate this treatment with an analysis of until and suggest a treatment of the interaction of negation with adverbials. Finally I discuss how this treatment can be extended to other prepositions, such as for and in.

Karttunen [1974] (following Lakoff [1969], Lindholm [1969], Horn $[1971 ; 1972]$, and others) proposes that until is ambiguous between a durative until and a punctual, negative-polarity item. Consider the following sentences from Karttunen [1974] ${ }^{1}$ :

(1) The princess slept until the prince kissed her.

(2) \#The princess woke up until the prince kissed her.

In (1), [The princess slept] describes an eventuality ${ }^{2}$ with a certain duration, and combines amicably with the until phrase. In (2), [The princess woke up] describes a punctual eventuality, and the combination is infelicitous. These examples are characteristic of durative until. When (2) is negated, however, as in (3), Karttunen argues that the acceptability of the resulting sentence is due to the presence of punctual, negative-polarity until.

(3) The princess didn't wake up until the prince kissed her.

Mittwoch [1977] (following Klima [1964], Fillmore [1968], Smith [1970], Heinämäki [1974], Seuren [1974], and others) disagrees, and instead argues that until is unambiguously durative. Crucially, this treatment analyzes negated eventualities as duratives. 
Both treatments, however, fail to adequately characterize durativity. Accomplishments such as [eat a sandwich] have duration, but are nevertheless infelicitous with until adverbials, as in (4):

(4) \#Joe ate a sandwich until noon.

Also, if until selects for a punctual item when in a negative environment, as Karttunen claims, then a durative item is predicted to be incompatible with until in such an environment. The acceptability of the durative [Joe sleeps] in (5) shows this prediction to be incorrect.

(5) Joe didn't sleep until midnight.

Karttunen might avoid this problem by saying that the matrix verb phrase describes an inchoative (and therefore punctual) eventuality in such cases. Sentence (5), for example, it would be understood that Joe begins to sleep at midnight, interpreting [Joe sleeps] as an inchoative achievement.

There is another problem, however. Karttunen points out that when a sentence with an until adverbial is negated there is a shift in what he calls the "focus" of the sentence. In positive sentences such as (6), the event described by the matrix sentence occurs before the time indicated by the until phrase, but in negated sentences such as (7) the event occurs at or after that time. As evidence of this shift, Karttunen contrasts the acceptability of (6) and (7) with the phrase [at the earliest]:

(6) She slept until noon \#[at the earliest].

(7) She didn't wake up until noon [at the earliest].

Mittwoch suggests that the shift may be due to implicature, but both Karttunen and Mittwoch agree that these data are puzzling.

In the following pages I will describe a characterization of the aspectual classes and of the selectional properties of temporal adverbials which avoids the above incorrect predictions. After motivating this treatment for positive sentences I'll propose a treatment of the interaction of negation with temporal adverbials to explain this "shift of focus".

\section{Background}

The categorization of verbs shown below can be traced as far back as Aristotle, and has since been examined by Ryle [1949], Kenny [1963], Taylor [1977] and Dowty $[1979 ; 1986]$, among others. 


\begin{tabular}{cccc} 
Statives & Activities & Accomplishments & Achievements \\
\hline know & run & draw a circle & recognize \\
love & write & build a house & reach the top \\
be hungry & sleep & eat a sandwich & wake up
\end{tabular}

Vendler [1967] and Dowty [1979] give a series of tests to determine the category of a specific verb, including tests for the acceptability of a verb with certain temporal adverbials such as for and in.

Dowty's [1986] definitions of the aspectual classes, originally from Taylor [1977], are repeated below.

- A sentence $\phi$ is stative iff it follows from the truth of $\phi$ at an interval $I$ that $\phi$ is true at all subintervals of $I$. (e.g., if John was asleep from 1:00 until 2:00 PM, then he was asleep at all subintervals of this interval: be asleep is a stative).

- A sentence $\phi$ is an activity (or energeia) iff it follows from the truth of $\phi$ at an interval $I$ that $\phi$ is true of all subintervals of $I$ down to a certain limit in size (e.g. if John walked from 1:00 until 2:00 PM, then most subintervals of this time are times at which John walked; walk is an activity.)

- A sentence $\phi$ is an accomplishment/achievement (or kinesis) iff it follows from the truth of $\phi$ at an interval $I$ that $\phi$ is false at all subintervals of $I$. (e.g. if John built a house in exactly the interval from September 1 until June 1, then it is false that he built a house in any subinterval of this interval: build a house is an accomplishment/achievement.)

Treatments of the selectional properties of temporal adverbials often rely on definitions based on an interval semantics, such as these. I claim that when discussing the interaction of adverbials with aspect it is necessary to refer not only to the interval over which the event occurs, but also to other properties of the event, such as whether it culminates. I'll now construct a description of the aspectual classes which incorporates certain basic properties of events into the Dowty [1986]/ Taylor [1977] aspectual classes.

\section{Termination Points}

Certain past tense sentences entail that the eventuality they describe has ended. Aspect is an indicator of the existence of this entailment: Accomplishment and achievement sentences, as in (8), have this entailment, and activity and stative sentences, as in (9), do not. 
(8) Joe [ate his sandwich] this morning.

Joe [recognized Bill] this morning.

(9) Joe [jogged] this morning.

Irene [was happy] this morning.

I will say, following Kamp and Rohrer [1990], that accomplishments and achievements have well-defined termination points. Conversely, activities and statives have poorly-defined termination points.

We can test for the presence of a well-defined termination point by combining a statement which implies that a certain eventuality has terminated with a statement that cancels that implicature. The result is contradictory only when the eventuality has a well-defined termination point:

(10) Activity: Did Joe [jog] this morning? Yes, and he's still jogging. ( $\Rightarrow$ poorly-defined termination)

(11) Accomplishment: Did Joe [eat his sandwich] this morning? \#Yes, and he's still eating his sandwich. ( $\Rightarrow$ well-defined termination)

I propose that Dowty's framework be complemented by the following:

(12) - If a sentence is an activity or a stative then it is true over an interval with a poorly-defined termination point.

- If a sentence is an accomplishment/achievement then it is true over an interval (or "preparatory period") with a well-defined termination point.

For example, if an accomplishment sentence $\mathbf{P}$ is true over an interval $\mathbf{P}_{t}$, then $\mathbf{P}_{\boldsymbol{t}}$ is an interval with a well-defined termination point and $\mathbf{P}$ is false at all subintervals of $\mathbf{P}_{\boldsymbol{t}}$.

Temporal prepositions order their arguments

Consider the sentences [Joe ate oysters] and [George brought out

the sushi]. Because these sentences represent eventualities with no intrinsic interdependency, they can occur in either order, or they can co-occur.

Consider their ordering in the following sentences:

(13) [Joe ate oysters] before [George brought out the sushi].

(14) [Joe ate oysters] until [George brought out the sushi].

(15) [Joe ate oysters] after [George brought out the sushi].

(16) [Joe ate oysters] while [George brought out the sushi]. 
As the preposition varies, the order of the events vary. With such intuitions, the prepositions which head temporal adverbials can be divided, roughly, into the following classes:

- Class I. Prepositions which place A prior to B: before, until

- Class II. Prepositions which place B prior to A: after

- Class III. Prepositions which place A concurrently with B: while, at, during, for

This tentative classification predicts that a sentence containing a temporal adverbial will be nonsensical if world knowledge or context forces it to take on an ordering of events contrary to that specified by the preposition heading that adverbial. Specifically, if $\mathbf{P}_{\boldsymbol{i}}$ is a preposition of class $i$, and $\mathbf{A}_{\boldsymbol{e}}$ and $\mathbf{B}_{\boldsymbol{e}}$ are the eventualities represented by phrases $\mathbf{A}$ and $\mathbf{B}$, respectively, such that $\mathbf{A}_{\boldsymbol{e}}$ must occur after $\mathbf{B}_{\boldsymbol{e}}$, then sentences of the form [A $\mathbf{P}_{I} \mathbf{B}$ ] and [B $\mathbf{P}_{I I} \mathbf{A}$ ] are predicted to be nonsensical. These predictions are upheld in the following examples:

(17) \#[Joe got into the car] before Ihe opened the car door].

(18) \#[The bucket overflowed] until I [Joe poured water into it].

(19) \#[Joe opened the car door] after II [he got into the car].

Also, if $\mathbf{A}$ cannot co-occur with $\mathbf{B}$, then sentences of the form [A $\mathbf{P}_{I I I} \mathbf{B}$ ] are predicted to be nonsensical, as in (20):

(20) \#[Joe called the plumber] while ${ }_{I I I}$ [the phone was dead].

The prepositions at, during, and for subcategorize for an NP complement rather than a sentential complement. In a sentence such as [Joe was home at 2PM], the classification of the preposition at requires that the stative described by the phrase [Joe was home] must temporally coincide with 2PM. Any contradiction of this coincidence is predicted be nonsensical, as below:

(21) [Joe was home] at [2PM]. \#...He was at school all afternoon.

(22) [Joe was home] during [Irene's hockey practice this morning]. \#...He arrived home at noon.

(23) [Joe was home] for [the dinner hour]. \#...He arrived at home at midnight. 
I'll conclude that in sentences of the form [A $\mathbf{P}_{\boldsymbol{i}} \mathbf{B}$ ], the preposition $\mathbf{P}_{\boldsymbol{i}}$ determines the temporal order of the eventualities $\mathbf{A}_{e}$ and $\mathbf{B}_{e}$.

If there are three ways to order eventualities, then a language only needs three prepositions for this purpose. Our classification of English prepositions lists seven of them, however, and there are many more. By way of explanation of this overabundance, consider the following sentences:

(24) Joe ate his sandwich [before noon] / \#[until noon].

(25) Irene recognized Bill [at noon] / \#[during noon].

(26) Irene read the paper \#[at her lunch hour] / [during her lunch hour].

These sentences are acceptable with one preposition of a class but not with another, suggesting the existence of a subtle difference in usage or meaning of the prepositions within a class ${ }^{3}$. Before discussing in detail the selectional properties of until and its manner of relating intervals, I will introduce the following terminology:

In the DRT treatment of tense, a sentence introduces an event into the discourse (Hinrichs [1981], Partee [1984]). I will say that a sentence (or temporal phrase) $\mathbf{A}$ introduces into the discourse an event $\mathbf{A}_{e}$, and that that event is true over the interval $\mathbf{A}_{t}$ as per the description of the aspectual classes given in (12). $\mathbf{A}_{t}$ corresponds to the notion of event time in Reichenbach's [1947] temporal analysis.

I can now refine my statement of the above conclusion as follows: In a sentence of the form [A $\mathbf{P}_{\boldsymbol{i}} \mathbf{B}$ ], the phrases $\mathbf{A}$ and $\mathbf{B}$ introduce the events $\mathbf{A}_{\boldsymbol{e}}$ and $\mathbf{B}_{e}$, respectively, into the discourse, and $\mathbf{P}_{i}$ orders $\mathbf{A}_{t}$ and $\mathbf{B}_{t}$, which are intervals defined as in (12). Consider the following example:

(27) [Joe got into the car] after [he opened the car door].

The $\mathbf{A}$ argument of after, [Joe got into the car], introduces an accomplishment $\mathbf{A}_{e}$ which occurs on the interval $\mathbf{A}_{t}$, an interval with a well-defined termination point. The $B$ argument, [he opened the car door], introduces a $\mathbf{B}_{e}$ which occurs on the interval $\mathbf{B}_{t}$, also an interval with a well-defined termination point. The preposition after then orders $\mathbf{A}_{t}$ and $\mathbf{B}_{t}$ (and therefore $\mathbf{A}_{e}$ and $\mathbf{B}_{e}$ ) temporally.

Until

We are now prepared to explore in detail the selectional properties of until and the manner in which it orders eventualities.

Eventualities which are true over an interval with a poorly-defined termination point are felicitous with until adverbials: 
(28) Activity: [Joe swam] until noon.

(29) Stative: [Joe was hungry] until noon.

Eventualities which are true over an interval with a well-defined termination point are infelicitous with until adverbials:

(30) Accomplishment: \#[Joe ate a sandwich] until noon.

(31) Achievement: \#[Joe recognized] Irene until noon.

(32) Inchoative achievement: \#[Joe started swimming] until noon.

These data lead us to conclude that, in a sentence of the form [A until B], $\mathbf{A}_{t}$ must be an interval with a poorly-defined termination point ${ }^{4}$. Note that this generalization is an improvement over the statement that until selects for a durative eventuality in that we can now include accomplishments in the class of eventualities which are infelicitous with until.

The only phrases acceptable as the prepositional object of until are those which introduce an eventuality true over an interval which is or contains a well-defined termination point:

(33) Point in time: Joe kept working until [noon].

(34) Achievement: Joe kept working until [he realized it was lunchtime].

(35) Accomplishment: Joe was homeless until [Irene built him a house].

(36) Activity: \#Joe watched TV until [Irene kept working].

Until ignores any preparatory period and selects for the well-defined point within $\mathbf{B}_{t}$. To distinguish the interval $\mathbf{B}_{t}$ (the entire interval over which $\mathbf{B}_{e}$ occurs) from that portion of $\mathbf{B}_{t}$ selected for by until, I'll refer to the well-defined point within $\mathbf{B}_{t}$ as $\mathbf{B}_{t_{w}}$.

Until also orders its arguments. If the sentence [A until $B$ ] is true, then implying that $\mathbf{A}_{e}$ occurs after $\mathbf{B}_{t_{\omega}}$ is nonsensical, as in (37):

\#Joe swam until noon, starting at 1:00 PM.

and implying that $\mathbf{A}_{e}$ occurs before $\mathbf{B}_{t_{w}}$ but doesn't continue to the point $\mathbf{B}_{t_{w}}$ is also nonsensical, as in (38):

(38) Joe swam until noon. \#In fact, he swam until 11:30.

We can conclude that until combines with $\mathbf{B}_{t_{\omega}}$ to indicate a position in which to place $\mathbf{A}_{e}$, and that that position is the interval whose final point is $\mathbf{B}_{t_{w}}$.

This placement of $\mathbf{A}_{e}$ before $\mathbf{B}_{t_{\omega}}$ will create the (defeasible) implicature that $\mathbf{A}_{t}$ does not continue beyond $\mathbf{B}_{t_{w}}$, i.e., $\mathbf{A}_{t}$ is supplied with a well-defined 
termination point. Because of this, until does not combine with an $\mathbf{A}_{t}$ which already has a well-defined termination point. The selectional properties of until can therefore be seen as a side effect of until's ordering operation. The final analysis is as follows:

(39) In a sentence of the form [A until B], until selects for a point $\mathbf{B}_{t_{w}}$ which is well-defined. Until places $A_{e}$ in the interval terminating at $\mathbf{B}_{t_{w}}$. Schematically,

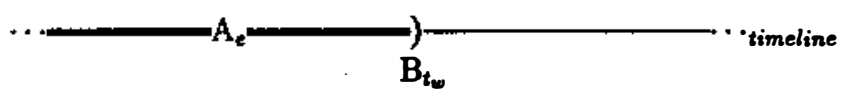

The ellipsis in the above diagram represents a poorly-defined endpoint, and the round bracket indicates a well-defined endpoint. I will use a square bracket to indicate inclusion of an endpoint in an interval and a round bracket to indicate exclusion of that endpoint.

In (40), for example, $A_{e}$ is the state of Joe being homeless, and until indicates that $\mathbf{A}_{e}$ occurs in the interval terminating at $\mathbf{B}_{t_{w}}$, the point at which the house is complete. Dowty's definition of statives tells us that $\mathbf{A}$ is true at all subintervals of that interval.

(40) Joe was homeless until Irene built him a house.

This treatment correctly predicts that Joe is homeless while the house is being built and stops being homeless when the house is finished. This placement of $\mathbf{A}_{e}$ implies that $\mathbf{A}_{e}$ does not continue past $\mathbf{B}_{t_{w}}$. The implicature can be canceled, however, as in (41):

(41) Joe worked until noon. In fact, he worked until 1:00.

Sentences such as (42) appear to falsify the claim that until subcategorizes for an $\mathbf{A}_{t}$ with a poorly-defined endpoint:

(42) Joe [drove around the block] for an hour.

It has been noted by Moens and Steedman [1988], however, that a verb may change aspectual class through a process they call coercion. The accomplishment in (42) has been coerced into an activity via iteration of that accomplishment. An activity can also be coerced into an achievement. In (43), for example, [he was hungry] conforms to until's requirement that $\mathbf{B}_{t}$ contain a well-defined termination point by taking on an inchoative interpretation. 
(43) Joe kept working until [he was hungry].

\section{Negation}

I'll now turn to the shift of focus noted by Karttunen, and show how my treatment of adverbials provides an explanation for this phenomenon.

As stated above, in a positive sentence containing an until adverbial the eventuality described by the matrix sentence, $A_{e}$, occurs before the time indicated by the until adverbial, but, in the corresponding negative sentence, $A_{e}$ occurs at or after that time. In (44), for example, we are discussing an eventuality (i.e., the holding of the hostages) which occurs before the kidnapper's demands are met, and in (45) we are discussing an eventuality (i.e., the releasing of the hostages) which occurs after the demands are met.

(44) The kidnapper will hold the hostages captive until his demands are met.

(45) The kidnapper won't release the hostages until his demands are met.

As evidence of this shift of focus, Karttunen points out that the phrase [at the earliest] is acceptable with until only when the sentence is negated:

(46) She slept until 9 \#[at the earliest] / [at the latest].

(47) She didn't wake up until 9 [at the earliest] / \#[at the latest].

These data will support the notion that until aligns the eventuality introduced by the matrix sentence with an interval if we assume that the negation in (47) takes scope over the adverbial phrase (an assumption I'll discuss presently). I have argued that the preposition until combines with a $\mathbf{B}_{t}$ to produce an interval in which to place $\mathbf{A}_{e}$. If negation takes scope over the until adverbial, it will affect the interval produced by that adverbial, thereby affecting the position in which until places $\mathbf{A}_{\boldsymbol{e}}$.

How does negation affect this interval? Consider the examples below:

(48) Joe realized the answer, but not at noon.

(49) Joe was in his office, but not during the party.

In (48) the realization can occur at any point other than noon. In (49) Joe cannot be in his office during the interval over which the party takes place, and the implication is that he was in his office for some period before and/or after the party. I'll conclude that the effect of negation on an interval is to complement that interval, a conclusion consistent with Keenan and Faltz's treatment of negation as a complementation operator [Keenan and Faltz, 1985]. The complement of an interval will consist of all the points not included in that interval, schematically: 
The interval before 2:00

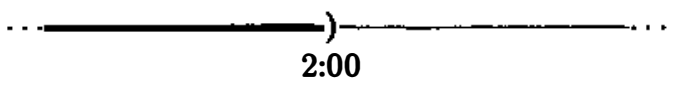

The complement of the above interval

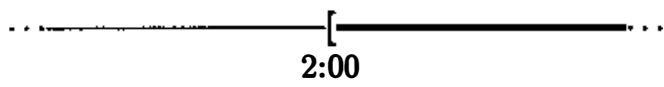

When negation takes scope over until, the interval that until indicates in which to place $\mathbf{A}_{e}$ is complemented, and $\mathbf{A}_{e}$ is placed in this new interval instead. This analysis correctly predicts that the focus of the sentence will shift to an event occurring on this new interval.

Consider the interpretation of sentence (50) where negation takes scope over the adverbial, as paraphrased in (51).

(50) Joe didn't sleep until midnight.

(51) Not until midnight did Joe sleep.

In (50), the phrase [until midnight] indicates that the potential placement of $\mathbf{A}_{e}$ is the interval terminating at midnight, as shown below.

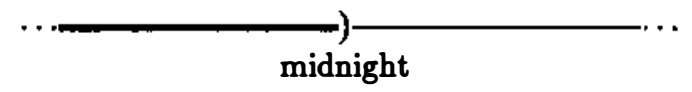

When negation takes scope over the until phrase this interval will be complemented, producing an interval whose initial point is at midnight. Until places $\mathbf{A}_{e}$ in this new interval, as below:

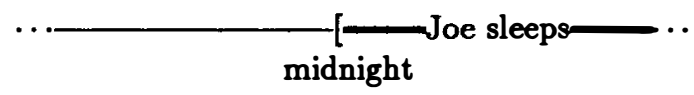

This placement implies that $\mathbf{A}_{e}$ begins at midnight, but context may cancel this implicature, allowing until to place $\mathbf{A}_{e}$ later within the interval, as in (52):

(52) Joe didn't sleep until midnight. In fact, he didn't sleep until 1:00AM.

Recall the difference in acceptability of the phrase [at the earliest] with negative and positive until sentences:

(53) She slept until 9 \#[at the earliest] / [at the latest].

(54) She didn't wake up until 9 [at the earliest] / \#[at the latest]. 
This contrast can be explained in light of my explanation of the shift of focus. Note that in (55a) [at the earliest] positions the initial point of Joe's swimming at noon, and in (55b) [at the latest] positions the final point.

(55) Joe swam for two hours.

a. At the earliest he was swimming at noon.

b. At the latest he was swimming at noon.

In (53), it is the final point of $\mathbf{A}_{e}$ that is aligned with $\mathbf{B}_{t_{w}}$, giving that point some measure of salience. The phrase [at the earliest] selects for an initial point and is therefore infelicitous. In (54), however, $\mathbf{A}_{e}$ has been repositioned so that its initial point is aligned with $\mathbf{B}_{t_{w}}$. In this case, [at the earliest] is acceptable.

As for the claim that the negation in sentences such as (56) takes scope over the until phrase, sentence (56) cannot be paraphrased in a manner corresponding to the sentential scope of negation, as in (57):

(56) Joe didn't wake up until noon.

(57) \#It is not true that Joe woke up until noon.

Also, if we let negation take scope over the verb phrase, we should get a reading in which there is no event of Joe's waking up. This reading is not available, however. The only remaining possibility is that the negation in (56) takes scope over the adverbial phrase ${ }^{5}$.

For

This treatment can be extended to for, avoiding certain problems with existing treatments. Dowty [1979] gives the following truth conditions for for:

(58) For $\left(\in P_{(I V / I V) /(t / i)}\right)$ translates into:

$$
\lambda P_{t} \lambda P \lambda x\left[P_{t} n \wedge \forall t[t \subseteq n \rightarrow A T(t, P x)]\right]
$$

If sentence (59) is true, for example, then there is a one hour interval I over which [Joe jogs] is true, and at all subintervals of $I$ [Joe jogs] is also true.

(59) Joe jogged for an hour.

As Dowty points out, (58) incorrectly predicts that activity sentences such as (59) will be ungrammatical because if an activity sentence is true over an interval $I$ it is not true at all subintervals of $I$, but only at subintervals down to a certain size. Dowty also notes that habitual and repetitive readings are erroneously ruled out by his analysis; again, (58) 
requires the $\mathbf{A}$ phrase to be true at every subinterval of $\mathbf{B}_{\boldsymbol{t}}$, disallowing gaps between repetitions of $\mathbf{A}_{e}$.

Moens and Steedman [1988] alternatively propose that a for adverbial selects for an activity ${ }^{6}$. This analysis incorrectly rules out the acceptability of stative sentences such as (60).

(60) Joe was hungry for several hours.

In an earlier paper, they suggest that a stative may be coerced into an activity in order to be felicitous with a for adverbial [Moens and Steedman, 1986]. However, if, in (60), Joe is hungry for an interval of several hours then Joe is hungry at all subintervals of that interval, indicating that [Joe is hungry] remains a stative sentence by definition.

An analysis of for along the lines of that proposed for until avoids these problems. This analysis of for requires an $\mathbf{A}_{t}$ of the same type as that of until: Eventualities which occur over an interval $\mathbf{A}_{t}$ with a poorly-defined termination point are felicitous with for.

(61) Activity: [Irene jogged] for an hour.

(62) Stative: [Joe was in a coma] for ten days.

Conversely, eventualities which occur over an interval $\mathbf{A}_{t}$ with a well-defined termination point are infelicitous with for:

(63) Accomplishment: \#[Joe took off his hockey skates] for twenty minutes.

(64) Achievement: \#[Joe recognized George] for two hours.

For, unlike until, selects for a $\mathbf{B}_{t}$ which is an interval rather than a point:

(65) Joe managed to stay awake for [the whole meeting].

(66) Joe swam for [two hours].

(67) \#Joe swam for [noon].

For aligns $\mathbf{A}_{e}$ with $\mathbf{B}_{t}$, and $\mathbf{A}_{e}$ must occupy the entire $\mathbf{B}_{t}$ interval. For example, the operation of for in sentence (68) is to place the eventuality of Joe's sleeping concurrent with the two hour interval, as shown below:

(68) Joe slept for two hours.

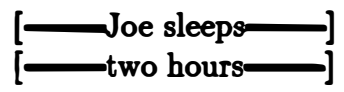


Dowty's definition of activities tells us that [Joe sleeps] is true at all subintervals of that two hour interval down to a certain size.

Sentence (68) implies that Joe slept for no longer than two hours, but, as with until, this implicature may be canceled, as in (69).

(69) Joe slept for two hours. In fact, he slept for three.

As with until, when negation takes scope over the for phrase, the interval which for indicates in which to place $\mathbf{A}_{e}$ is complemented. Consider sentence (70), below:

(70) Joe was happy, but not for the two hours his wallet was missing.

Complementing the two hour interval shown in (71), we get the interval in which for will place [Joe is happy], as shown in (72):

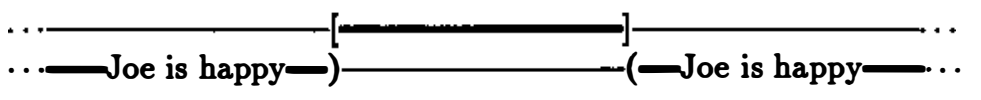

A common interpretation of a negated for sentence is that there are not two intervals during which $\mathbf{A}_{e}$ occurs, but only the later of the two intervals. One interpretation of sentence (73) is that I'll be in my office two hours from the speech time [Reichenbach, 1947].

(73) I'll be in my office, but not for two hours.

(74) I arrived at my office, but not for two hours.

In (74), I arrive at my office two hours after the reference time.

Hinrichs [1985] proposes an alternate solution to Dowty's problem. His truth conditions for for are based on a lattice-theoretic approach to events. Using an operator analogous to Carlson's [1977] realization operator, he breaks events into "event stages" and redefines Dowty's truth conditions for for and in to map these stages onto the interval specified by the for phrase. In this manner he allows gaps, such as those occurring in activities and habituals, in the eventualities selected for by for and in.

In the treatment of prepositions I have proposed, prepositions don't refer to the subintervals of an interval over which a sentence is true. Instead, the eventuality introduced by the sentence is placed in the interval indicated by the adverbial. Whether the sentence is true or false at certain subintervals of that interval depends on Dowty's definition of the aspectual class of that sentence. In this manner the correct predictions concerning activities are made, and yet the activity retains the properties specified by its definition. 
The correct predictions are also made concerning habitual sentences. Using the test given in (12), we find that habitual sentences introduce eventualities which are true over intervals with poorly-defined termination points:

(75) Irene [jogged] for five years. In fact, she still jogs. ( $\Rightarrow$ poorly-defined termination)

These sentences are correctly predicted to be acceptable with for-phrases.

$\underline{\text { In }}$

In this section, I'll briefly describe how my treatment can be extended to deal with in.

In requires $A_{t}$ to be or contain a well-defined point $A_{t w}$ (the same selectional property that until has for its $\mathbf{B}_{t}$ ), and $\mathbf{B}_{t}$ to be a time segment (the same as for). In aligns $\mathbf{A}_{t}$ with the last point of $\mathbf{B}_{t}$. The initial point of $A_{t}$ is constrained by speech time or by some contextually determined reference time. In (76), for example, there is some ten minute period $\mathbf{B}_{t}$ beginning at a contextually determined reference time, and $\mathbf{A}_{t_{w}}$ is placed at the end of $\mathbf{B}_{t}$, the point of realization.

(76) Joe realized the answer in ten minutes.

$$
[\text { Ten minutes_ }] \Leftarrow \text { realizes }
$$

The ambiguity displayed by in in sentences with future tense is explained by this treatment. For example, consider (77):

(77) Joe will build a house in two months.

This sentence has two interpretations: one in which Joe completes the building within a two-month period, as shown below:

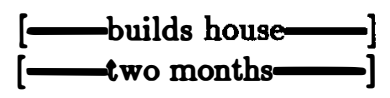

and the inchoative interpretation in which Joe begins the building at the end of a 2 month period:

$$
[\text { [wo months__ }] \Leftarrow \text { begin to build }
$$


When negation takes scope over the in adverbial, the point indicated by in in which to place $\mathbf{A}_{t \omega}$ is complemented. In sentence (78), for example, the point at which in wants to place the culmination of Joe's building of the house is the final point of $\mathbf{B}_{t}$, as shown, enclosed in brackets, in (79).

(78) Joe didn't build the house in ten months.

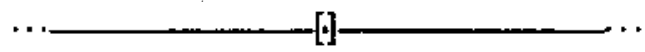

The complement of this point is shown in (80):

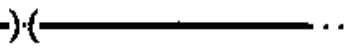

$\mathbf{A}_{t_{\boldsymbol{w}}}$ is placed somewhere in these new intervals. A paraphrase of such a placement is given in (81).

(81) Joe didn't build the house in ten months; he built it in nine.

\section{Conclusions}

In summary, I have proposed a treatment of the prepositions which head temporal adverbials as binary operators with selectional properties based on an extended version of the Dowty/Taylor definitions of the aspectual classes and as operators which order their arguments temporally. I have shown that this treatment avoids problems encountered by existing treatments of temporal adverbials, and explains certain facts with respect to the interaction of negation with these adverbials.

One issue raised by this treatment of adverbials is that of compositionality. If until selects for an $\mathbf{A}_{t}$ with a poorly-defined termination point and supplies it with a well-defined termination point, this new interval should serve as acceptable input to in adverbials, which select for an $\mathbf{A}_{t}$ with a well-defined termination point. Sentences such as (82) are unacceptable, however:

(82) \#Joe slept until noon in two hours.

The difference between eventualities which culminate and eventualities which don't build to a culmination but simply terminate must be explored. How this difference can be formalized is a matter for future research.

Another issue is whether achievements should be characterized as having an associated preparatory period. Recall that, when negation takes scope over an until adverbial causing a shift in focus, eventualities of all aspectual 
classes are acceptable as $\mathbf{A}_{e}$. The initial point of $\mathbf{A}_{t}$ is placed concurrently with $\mathbf{B}_{t_{w}}$, causing that initial point to become well-defined. I have assumed that it is only possible for a poorly-defined endpoint to become well-defined, and my treatment depends on this assumption. As a result, I can only explain the acceptability of achievements in these contexts by assuming that achievements have a preparatory period, however negligible that period is. That preparatory period will be an interval whose final point is the culmination of the achievement and whose initial point is, crucially, poorly-defined.

This is not necessarily a problem, and, in fact, Dowty [1986] places achievements in the same class as accomplishments, which do have associated preparatory periods. Karttunen [1974], Mittwoch [1977], Moens and Steedman [1988], and Vendler [1967] treat achievements as punctual, however, and I thought it worth mentioning that doing so will create complications for my treatment.

\section{Acknowledgements}

I am grateful to Alessandro Zucchi, Greg Carlson and Massimo Poesio for their helpful advice and criticism during the development of this proposal.

This material is based upon work supported by the National Science Foundation user grant number IRI-9003841.

\section{Footnotes}

${ }^{1}$ I will use the symbol "\#" to indicate a sentence in which the combination of the matrix clause and the adverbial (either in the same sentence or in the same context) is nonsensical or otherwise infelicitous.

2 I will use the term eventuality (from Bach [1981]) to refer to an element of the set of achievements, accomplishments, activities, and statives.

3 In fact, it has been suggested by [Allen, 1983], and later proven by [Ladkin, 1987], that there are 13 ways for two intervals to relate temporally.

' Kamp and Rohrer [1990] propose a similar analysis for jusqu'à, the French word for until.

5 It has been proposed ( [Jackendoff, 1972], [Kratzer, 1989]) that negation may also "focus" on a phrase within its scope, e.g., on the subject, as in:

i. JOE didn't sleep until noon; IRENE did.

or on the prepositional object of until:

ii. Joe didn't sleep until NOON; he slept until THREE.

I believe that treating negation as a generalized complementation operator (as Keenan and Faltz [1985] do) may also explain these cases; however, given 
that focus phenomena are still poorly understood (see, however, Rooth [1985], Krifka [1991], and Partee [1991]) I won't discuss this issue further.

${ }^{6}$ Moens and Steedman refer to activities as processes.

\section{References}

Allen, James (1983). Maintaining Knowledge About Temporal Intervals. Communications of the ACM 26(11):832-843.

Bach, Emmon (1981). On Time, Tense, and Aspect: An Essay in English Metaphysics. In Cole, P., ed., Radical Pragmatics. Academic Press, New York.

Carlson, Gregory N. (1977). A Unified Analysis of the English Bare Plural. Linguistics and Philosophy 1:413-457.

Dowty, David R. (1979). Word Meaning and Montague Grammar. D. Reidel, Dordrecht, Holland.

Dowty, David R. (1986). The Effects of Aspectual Class on the Temporal Structure of Discourse: Semantics or Pragmatics? Linguistics and Philosophy 9(1).

Fillmore, C.J. (1968). Types of Lexical Information. In Studies in Syntax and Semantics. Dordrecht: Reidel.

Heinämäki, Orvokki (1974). Semantics of English Temporal Connectives. Unpublished Ph.D. Dissertation, University of Texas at Austin.

Hinrichs, Erhard W. (1981). Temporale anaphora in englischen. StaatsExamen thesis, Universität Tubingen.

Hinrichs, Erhard W. (1985). A Compositional Semantics for Aktionsarten and NP Reference in English. Ph.D. Dissertation, The Ohio State University.

Horn, Laurence (1971). Negative Transportation: Unsafe at Any Speed? In Papers from the Seventh Regional Meeting of the Chicago Linguistics Society, Chicago, IL. 
Horn, Laurence (1972). On the Semantic Properties of Logical Operators in English. Ph.D. Dissertation, University of California, Los Angeles. Unpublished.

Jackendoff, Ray (1972). Semantic Interpretation in Generative Grammar. MIT Press, Cambridge, MA.

Kamp, Hans and Rohrer, Christian (1990). Untitled manuscript on tense and texts.

Karttunen, Lauri (1974). Until. Papers from the 10th Regional Meeting of the Chicago Linguistic Society, Chicago, IL.

Keenan, Edward L., and Faltz, Leonard M. (1985). Boolean Semantics for Natural Languages. D. Reidel Publishing Company, Dordrecht, Holland.

Kenny, Anthony (1963). Actions, Emotion, and Will. Humanities Press.

Klima, Edward (1964). Negation in English. In The Structure of Language. J. Katz and J. Fodor, eds. Prentice-Hall, Inc., Englewood Cliffs, NJ.

Kratzer, Angelica (1989). An Investigation of the Lumps of Thought. Linguistics and Philosophy 12:607 - 653.

Krifka, Manfred (1991). A Compositional Semantics for Multiple Focus Constructions. In proceedings SALT-91, Cornell Working Papers.

Ladkin, P. (1986). Time Representation: A Taxonomy of Interval Relations. In Proceedings of the Fifth National Conference on Artificial Intelligence, Philadelphia, Pennsylvania. pp. 360-366.

Ladkin, Peter (1987). The Logic of Time Representation. Ph.D. Dissertation, University of California, Berkeley. Unpublished.

Lakoff, Robin (1969). A Syntactic Argument for Negative Transportation. In Papers from the Thirteenth Regional Meeting of the Chicago Linguistics Society, Chicago, IL.

Lindholm, James M. (1969). Negative Raising and Sentence 
Pronominalization. In Papers from the Thirteenth Regional Meeting of the Chicago Linguistics Society, Chicago, IL.

Mittwoch, Anita (1977). How to Refer to One's Own Words. Journal of Linguistics 13:177-189.

Moens, Marc and Steedman, Mark (1986). Temporal Information and Natural Language Processing. Technical Report EUCCSS/RP-2, Center for Cognitive Science, University of Edinburgh.

Moens, Marc and Steedman, Mark (1988). Temporal Ontology and Temporal Reference. Association for Computational Linguistics 14(2):15-28.

Partee, Barbara (1984). Nominal and Temporal Anaphora. Linguistics and Philosophy 7:243 - 286.

Partee, Barbara (1991). Topic, Focus and Quantification. In proceedings SALT-91, Cornell Working Papers.

Reichenbach, Hans (1947). Elements of Symbolic Logic. McMillan.

Rooth, Mats (1985). Association with Focus. Ph.D. Dissertation, University of Massachusetts, Amherst.

Ryle, Gilbert (1949). The Concept of Mind. Barnes and Noble, London.

Seuren, P.A.M. (1974). Negative's Travels. In Semantic Syntax, P.A.M. Seuren, ed. Oxford: OUP.

Smith, Steven B. (1970). The Semantics of Negation. Ph.D. Dissertation, University of California, Los Angeles. Unpublished.

Taylor, Barry (1977). Tense and Continuity. Linguistics and Philosophy 1:199-220.

Vendler, Zeno (1967). Linguistics in Philosophy. Cornell University Press, New York. 
Janet Hitzeman

Linguistics Program

392 Dewey Hall

University of Rochester

Rochester, NY 14627

HITZEMAN@CS.ROCHESTER.EDU 